\title{
Penerapan Metode Waterfall Pada Pembelian Bahan Baku Produksi PT. Cam Jaya Abadi
}

\author{
Rahayu Ningsih ${ }^{1}$, Amelia Istiqomah $^{2}$, Wina Yusnaeni ${ }^{3}$, Titik Misriati ${ }^{4}$ \\ 1,2,3,4 Universitas Bina Sarana Informatika \\ Email: ${ }^{1}$ rahayu.ryh@ bsi.ac.id, ${ }^{2}$ istiqomah_amelia@gmail.com, ${ }^{3}$ wina.wyi@bsi.ac.id, ${ }^{4}$ titik.tmi@bsi.ac.id

\begin{tabular}{ccc}
\hline Diterima & Direvisi & Disetujui \\
$05-05-2020$ & $10-05-2020$ & $20-05-2020$ \\
\hline
\end{tabular}

\begin{abstract}
Abstrak - Dalam era globalisasi sekarang ini ilmu pengetahuan dan teknologi informasi berkembang dengan sangat cepat. Membuat perusahaan harus mencari cara agar tetap mampu bersaing didalam dunia bisnis, PT. Cam Jaya Abadi adalah perusahaan yang bergerak dibidang pembuatan palet kayu,furniture, exterior dan interior yang telah berpengalaman dibidang perkayuan. Pembelian bahan baku yang berjalan di PT. Cam Jaya Abadi masih sangat sederhana dari mulai proses permintaan barang sampai dengan pembuatan laporan. Dengan sistem yang ada tersebut sering terjadi kesalahan pada persediaan barang, kehilangan dokumen dikarenakan penyimpanan dokumen transaksi yang tidak baik, dan sering terjadi kesalahan informasi pada proses pembayaran. Dari beberapa permasalahan yang ada, maka peneliti memberikan solusi yaitu dengan merancang sebuah sistem informasi pembelian bahan baku dengan metode Waterfall , design menggunakan UML (Unifield Modeling Language) dan pembuatan aplikasi dengan Java Neatbeans 7.1. Metode tersebut dipergunakan untuk mempermudah proses pembelian bahan baku tersebut, dapat mempersingkat waktu kerja karyawan, dapat menghasilkan data yang akurat, dan dapat dibuat laporan pembelian perbulannya.
\end{abstract}

Kata kunci : persediaan, UML, waterfall

\begin{abstract}
In the current era of globalization, science and information technology is developing very rapidly. Making companies have to find ways to remain able to compete in the business world, PT. Cam Jaya Abadi is a company engaged in the manufacture of wooden pallets, furniture, exterior and interior that has experience in the field of timber. Purchase of raw materials running at PT. Cam Jaya Abadi is still very simple from the process of requesting goods to making reports. With the existing system there is often an error in the inventory, loss of documents due to bad document storage transactions, and frequent misinformation in the payment process. Of the several problems that exist, the authors provide a solution that is by designing an information system for purchasing raw materials with the Waterfall method, design using UML (Unifield Modeling Language) and applications using Java Neatbeans 7.1.. The method is used to simplify the process of purchasing raw materials, can shorten the work time of employees, can produce accurate data, and can be made a monthly purchase report.
\end{abstract}

Keywords : inventory, UML, waterfall

\section{PENDAHULUAN}

Berdasarkan data BPS tahun 2017 pertumbuhan produksi insdutri manufaktur besar dan sedang naik sebesar $4 \%$ dan industri manufaktur mikro dan kecil naik sebesar $2.50 \%$ pada triwulan kedua pada tahun 2017 dari triwulan kedua tahun 2016, Badan Pusat Statistik (BPS) mencatat adanya pertumbuhan yang tinggi dari produksi industri manufaktur besar dan sedang (IBS) sebesar 5,51\% pada kuartal III 2017 jika dibandingkan dengan periode yang sama tahun lalu (year on year/yoy). Tumbuhnya IBS itu juga lebih tinggi bila dibandingkan dengan di kuartal II 2017 yang sebesar 3,89\% dan pada kuartal III 2016 yang sebesar $4,87 \%$. Kepala BPS Suhariyanto menyebut pertumbuhan itu disebabkan seluruh sektor industri mengalami perbaikan. Sektor manufaktur yang paling menunjukkan pertumbuhan signifikan ialah industri logam dasar dengan pertumbuhan sebesar 11,97\% (yоy).

Penelitian-penelitian sebelumnya yang sesuai dengan tema yang di angkat oleh peneliti, diantaranya adalah : penelitian yang dilakukan pada PT. Seyon Indonesia yang membahas mengenai persediaan bahan - baku produksi menggunakan metode waterfall dalam pembuatan aplikasinya (Chandra Ramdhani, Gaja, \& Ratnawati, 2018), penelitian yang dilakukan di PT. TSP juga membahas mengenai persediaan bahan baku produksi (Yusnaeni, Ningsih, \& Misriati, 2017), 
penelitian yang dilakukan pada perusahaan De Lapisa Cakes menggunakan metode waterfall dan menggunakan VB.NET dalam pembuatan aplikasinya (Nugraha, Syarif, \& Dharmawan, 2018), penelitian yang di lakukan pada Toko Zabidhi Bread menggunakan metode waterfall dalam menyelesaikan masalahnya dalam pembelian bahan baku (Mutiah, Septiany Khoirum dan Apriana, 2018), penelitian yang dilakukan pada PT Unipack Indosystem juga membuat sebuah aplikasi dalam menyelesaikan masalah persediaan barangnya (Hidayatun, Marlina, \& Adinata, 2019), penelitian pada PT Kiat Ananda Cold Storage juga didasarkan pada kebutuhan sebuah aplikasi dalam penyelesaian masalah bahan baku (Haryadi, Prasetyo, \& Aziz, 2018), penelitian selanjutnya juga membahas tentang dibutuhkannya sebuah sistem informasi persediaan bahan baku untuk meningkatkan pelayanan kepada pelanggan (Frieyadie, 2015), dan penelitian terakhir yang menjadi referensi dari peneliti adalah penelitian pada PT. Masterweb Network dimana dibuatkan sebuah aplikasi untuk mengatur atau mengawasi persediaan barang (Fiqran, Lubis, Informasi, \& Tinggi, 2015).

Perusahaan atau instansi skala besar maupun kecil bukan hanya membutuhkan sumber daya manusia yang berkualitas namun juga membutuhkan sistem komputerisasi yang baik. PT.Cam Jaya Abadi merupakan adalah sebuah perusahaan yang didukung oleh para tenaga ahli dan profesional yang tentu saja mengutamakan kualitas dan kuantitas serta efisiensi kepada seluruh klien. PT. Cam Jaya Abadi pada saat ini bergerak pada bidang produksi kemasan kayu/wooden and still pallets, sistem pembelian bahan baku masih di lakukan secara manual sehingga akan membutuhkan waktu yang lama dalam penyajian informasi, seluruh kegiatan pekerjaannya masih melakukan pengendalian manajemen serta informasi yang belum terkomputerisasi, sehingga kegiatan yang berlangsung kurang efektif dan efisien sehingga memperlambat laporan yang dihasilkan. Atas pertimbangan kondisi di atas maka peneliti mencoba mengkaji permasalahan pembelian dalam ruang lingkup pembelian bahan baku.

\section{METODE PENELITIAN}

Metode penelitian yang dilakukan pada penelitian ini terdiri dari metode pengumpulan data dan metode pengembangan software menggunakan waterfall.

A. Metode Pengumpulan Data

Metode pengumpulan data yang peneliti lakukan adalah :

1. Observasi

Peneliti melakukan penelitian, dengan melihat secara langsung proses pembelian, untuk memproleh keterangan yang jelas tentang pengolahan data dalam komputerisasi system transaksi pembelian bahan baku pada PT. Cam Jaya Abadi.

\section{Observasi}

Peneliti melakukan tanya jawab dengan devisidevisi yang terkait tentang pembelian yaitu bapak Panggih sebagai kepala gudang dan bapak Taofik sebagai bagian PPIC untuk mendapatkan informasi yang jelas tentang proses pembelian bahan baku.

3. Studi Pustaka (Literature)

Peneliti tidak lepas dari data yang terdapat dari buku-buku yang menjadi referensi seperti artikel ilmiah, jurnal ilmiah dan buku-buku lain yang berhubungan dengan penelitian ini.

\section{B. Metode Pengembangan Software}

Metode pengembangan software yang peneliti gunakan adalah metide waterfall, yaitu :

1. Analisis Kebutuhan Sistem

Dalam tahap ini penulis menganalisa kebutuhan dari para pengguna sistem terhadap aplikasi yang akan dikembangkan. Pengguna sistem yang di analisis kebutuhannya terhadap sistem yang akan dikembangkan adalah PPIC, Unit Pembahanan, Manager produksi, Accounting, Quality dan Direktur.

2. Desain

Dalam tahap ini peneliti melakukan desain berdasarkan analisis kebutuhan sistem menggunakan UML, yang terdiri dari : Use Case Diagram, Activity Diagram, ERD, LRS, Spesifikasi File, Software Architecture, User Interface, dan Spesifikasi Hardware dan Software.

3. Code Generation

Dalam tahap ini peneliti melakukan pembuatan database dengan MySQL, pembuatan pengkodean program dengan Java Neatbeans 7.1 dan Jdk 7u40.

4. Testing

Dalam tahap ini peneliti melakukan pengujian dengan menggunakan Black Box pada form login.

5. Support

Dalam tahap ini peneliti membuatkan halaman backup database, sehingga ketika terjadi kesalahan program, maka tidak akan berpengaruh terhadap data yang tersimpan.

\section{HASIL DAN PEMBAHASAN}

Berdasarkan metode pengembangan software yang peneliti lakukan adalah waterfall, diantaranya adalah sebagai berikut :

1. Analisis Kebutuhan Sistem

A. Halaman PPIC

A. 1. PPIC dapat melakukan validasi.

A. 2. PPIC dapat masuk ke menu utama.

A. 3. PPIC dapat membuka menu master.

A. 4. PPIC dapat mengelola data user.

A. 5. PPIC dapat mengelola data supplier.

B.Halaman Unit Pembahanan

B. 1. Unit pembahanan dapat melakukan validasi.

B. 2. Unit pembahanan dapat mengelola data barang. 
B. 3. Unit pembahanan dapat mencari data supplier.

B. 4. Unit pembahanan dapat melihat data supplier.

B. 5. Unit pembahanan dapat mengelola data permintaan.

C.Halaman Manager Produksi

C. 1. Manager produksi dapat melakukan validasi.

C. 2. Manager produksi dapat melihat data permintaan.

C. 3. Manager produksi dapat melihat data penawaran.

C. 4. Manager produksi dapat mnelihat pemesanan.

C. 5. Manager produksi dapat menyetujui pemesanan.

D.Halaman Accounting

D. 1. Accounting dapat melakukan validasi.

D. 2. Accounting dapat mengelola data pembayaran.

D. 3. Accounting dapat melihat data kedatangan barang.

D. 4. Accounting dapat melihat pengembalian barang.

D. 5. Accounting dapat melihat pemesanan.

E.Halaman Quality

E. 1. Quality dapat melakukan validasi.

E. 2. Quality dapat mengelola data kedatangan barang.

E. 3. Quality dapat mengelola pengembalian barang.

E. 4. Quality dapat melihat pemesanan.

E. 5. Quality dapat melihat penawaran.

F.Halaman Direktur

F. 1. Direktur dapat melakukan validasi.

F. 2. Direktur dapat melihat data pembayaran.

F. 3. Direktur dapat melihat laporan.

F. 4. Direktur dapat melihat pemesanan.

F. 5. Direktur dapat melihat penawaran.

2. Implementasi

1. Form Login

Form Login memiliki enam akses sesuai dengan pengguna yang menggunakan aplikasi ini, dan aksesnya dibatasi sesuai analisis kebutuhan sistem.

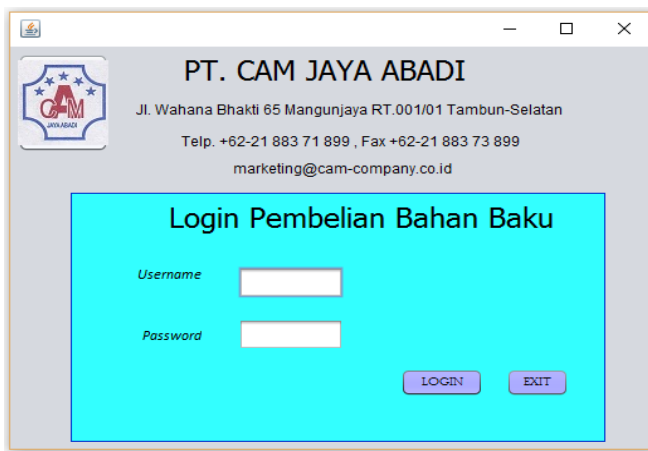

Sumber: Penelitian (2019)

Gambar 1. Form Login
2. Form Penawaran Harga

Form Penawaran Harga dipergunakan untuk mencatat penawaran harga barang yang dikirimkan oleh supplier.

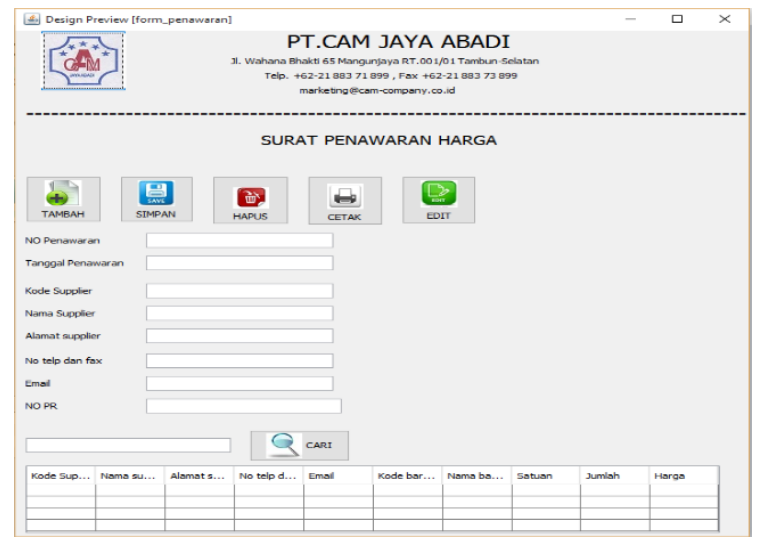

Sumber: Penelitian (2019)

Gambar 2. Form Penawaran Harga

\section{Form Pemesanan Barang}

Form Pemesanan Barang dipergunakan untuk mencatat pemesanan barang yang dikirimkan kepada supplier.

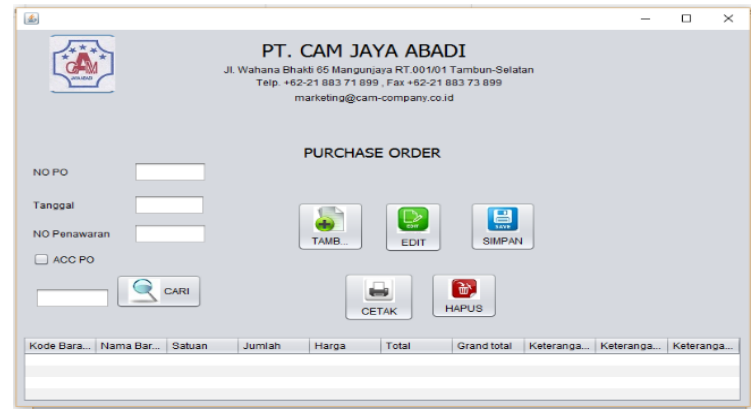

Sumber: Penelitian (2019)

Gambar 3. Form Pemesanan Barang

4. Form Pembayaran

Form Pembayaran dipergunakan untuk mencatat pembayaran penerimaan barang yang dikirimkan oleh supplier.

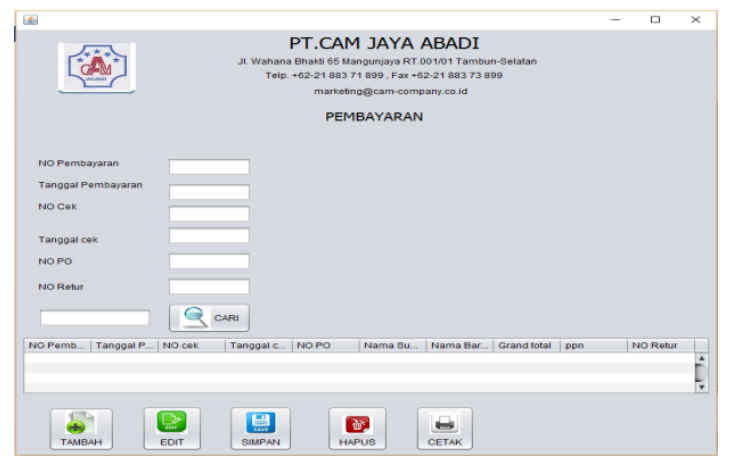

Sumber: Penelitian (2019)

Gambar 4. Form Pemesanan Barang 


\section{KESIMPULAN}

Dengan adanya sistem yang sudah terkomputerisasi user dapat melakukan validasi terhadap sistem dimana keamanan dan kerahasian data-data perusahaan akan aman, adanya menu master untuk mempermudah pencarian data barang, supplier, akun danuser. Adanya menu transaksi yang dapat membuka form permintaan dan dapat melihat kode permintaan yang menggunakan format penawaran, adanya format penomoran purchase order dengan kombinasi tanggal dan bulan transaksi. Adanya pencatatan kedatangan barang. Form retur untuk mencatat dan diberikan ke supplier jika ada kesalahan pada pengiriman barang, form pembayaran untuk mengetahui jumlah tagihan pembayaran, data laporan untuk mengetahui laporan transaksi pembelian.Direktur juga mampu mengetahui laporan pembelian dan pembayaran supplier. Dan direktur mampu mengontrol jumlah pembelian demi mengurangi cost Karena dengan adanya sistem yang mampu menyimpan semua laporan terlebih laporan keuangan.

Dari rancang bangun sistem informasi yang di kembangkan oleh peneliti, ada beberapa proses pada pembelian bahan baku yang masih perlu di kembangkan yaitu, di perlukannya pesan pengingat pembayaran kepada supllier agar tidak melebihi jatuh tempo, diperlukannya bukti cetakan untuk bukti potong pembelian bahan baku, monitoring outstanding pembelian baku.

\section{REFERENSI}

Chandra Ramdhani, E., Gaja, H., \& Ratnawati, R. (2018). Aplikasi Berbasis Dekstop Untuk Persediaan Bahan Baku Produksi Menggunakan Model Waterfall (Study Kasus: PT. Seyon Indonesia). Jurnal Informatika: Jurnal Pengembangan IT, 3(2), 277-284. https://doi.org/10.30591/jpit.v3i2.855
Fiqran, M., Lubis, B. O., Informasi, S., \& Tinggi, S. (2015). Isbn: 978-602-72850-6-4 Isbn : 978602-72850-6-4. Sniptek, 177-186.

Frieyadie, F. (2015). Pembangunan Sistem Informasi Inventory Menggunakan Linear Sequential Model Untuk Peningkatan Layanan Inventory Barang. Techno Nusa Mandiri, 12(2), 104-108. Retrieved from http://ejournal.nusamandiri.ac.id/ejurnal/index. $\mathrm{php} /$ techno/article/view/358

Haryadi, E., Prasetyo, F., \& Aziz, H. A. (2018). Perancangan Dan Implementasi Program Sistem Penerimaan Bahan Baku Makanan Cepat Saji ( Studi Kasus Pada Pt . Kiat Ananda Cold Storage ). 226-234.

Hidayatun, N., Marlina, S., \& Adinata, E. (2019). Perancangan Sistem Inventory Untuk Pengelolaan Data Persediaan Bahan Baku. 9(1), 11-22.

Mutiah, Septiany Khoirum dan Apriana, V. (2018). Penerapan Model Waterfall Pada Sistem Informasi Pembelian Bahan Baku Roti. Jurnal Perpektif, XVI No.2(2), 118-124. Retrieved from

http://ejournal.bsi.ac.id/ejurnal/index.php/pers pektif/article/view/3459/2681\%0Aejournal.bsi .ac.id

Nugraha, W., Syarif, M., \& Dharmawan, W. S. (2018). Penerapan Metode Sdlc Waterfall Dalam Sistem Informasi Inventori Barang Berbasis Desktop. JUSIM (Jurnal Sistem Informasi Musirawas), 3(1), 22-28. https://doi.org/10.32767/jusim.v3i1.246

Yusnaeni, W., Ningsih, R., \& Misriati, T. (2017). Pemilihan Suplier Bahan Baku Dengan Metode Technique for Order Performance by Similarity to Ideal Solution(TOPSIS). Seminar Nasional Sains Dan Teknologi, (November), $1-7$. 


\section{A. Use case Diagram PPIC}

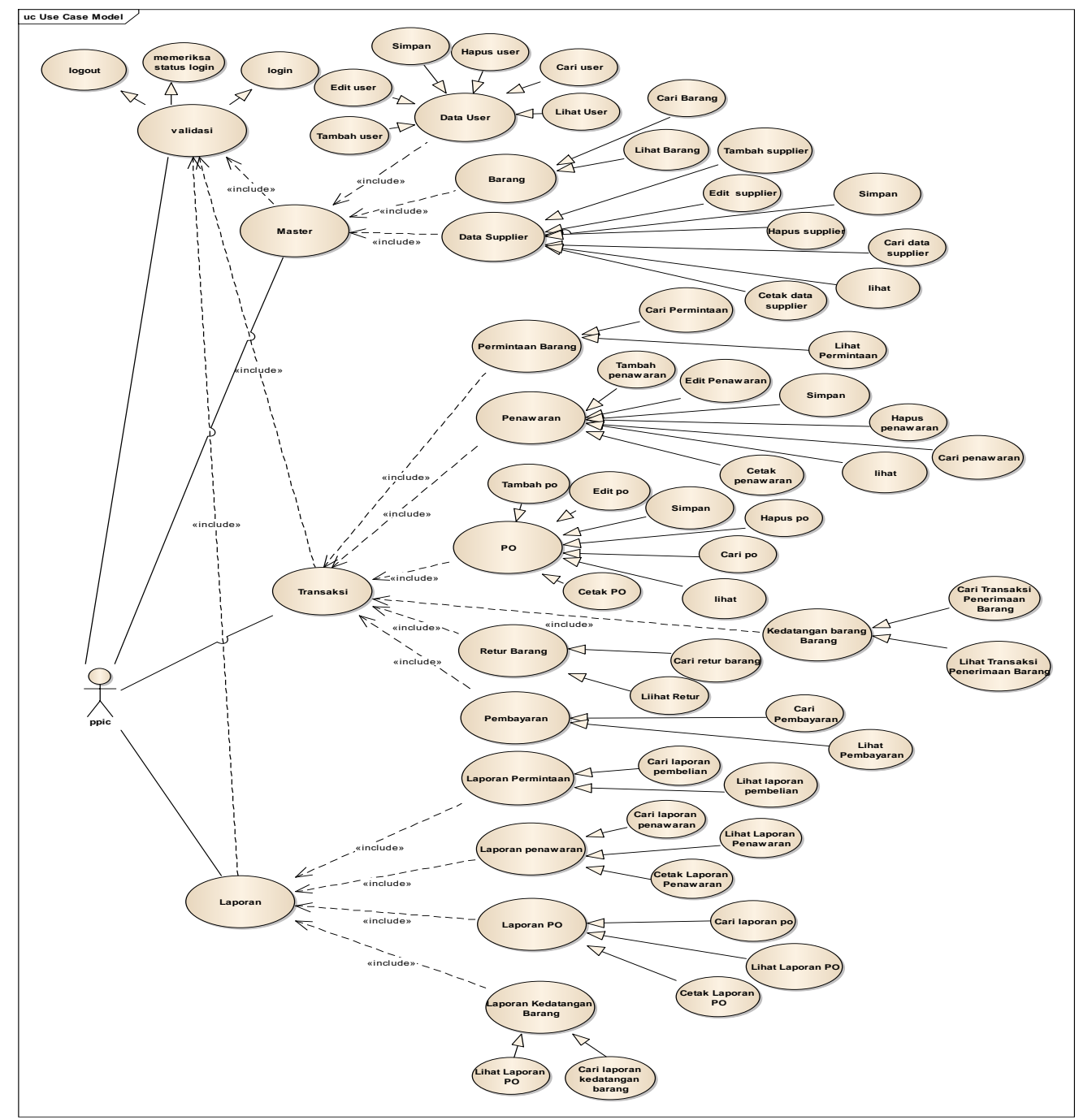

Sumber: Penelitian (2019)

Gambar 5. Use case Diagram PPIC 


\section{B. Activity Diagram Direktur}

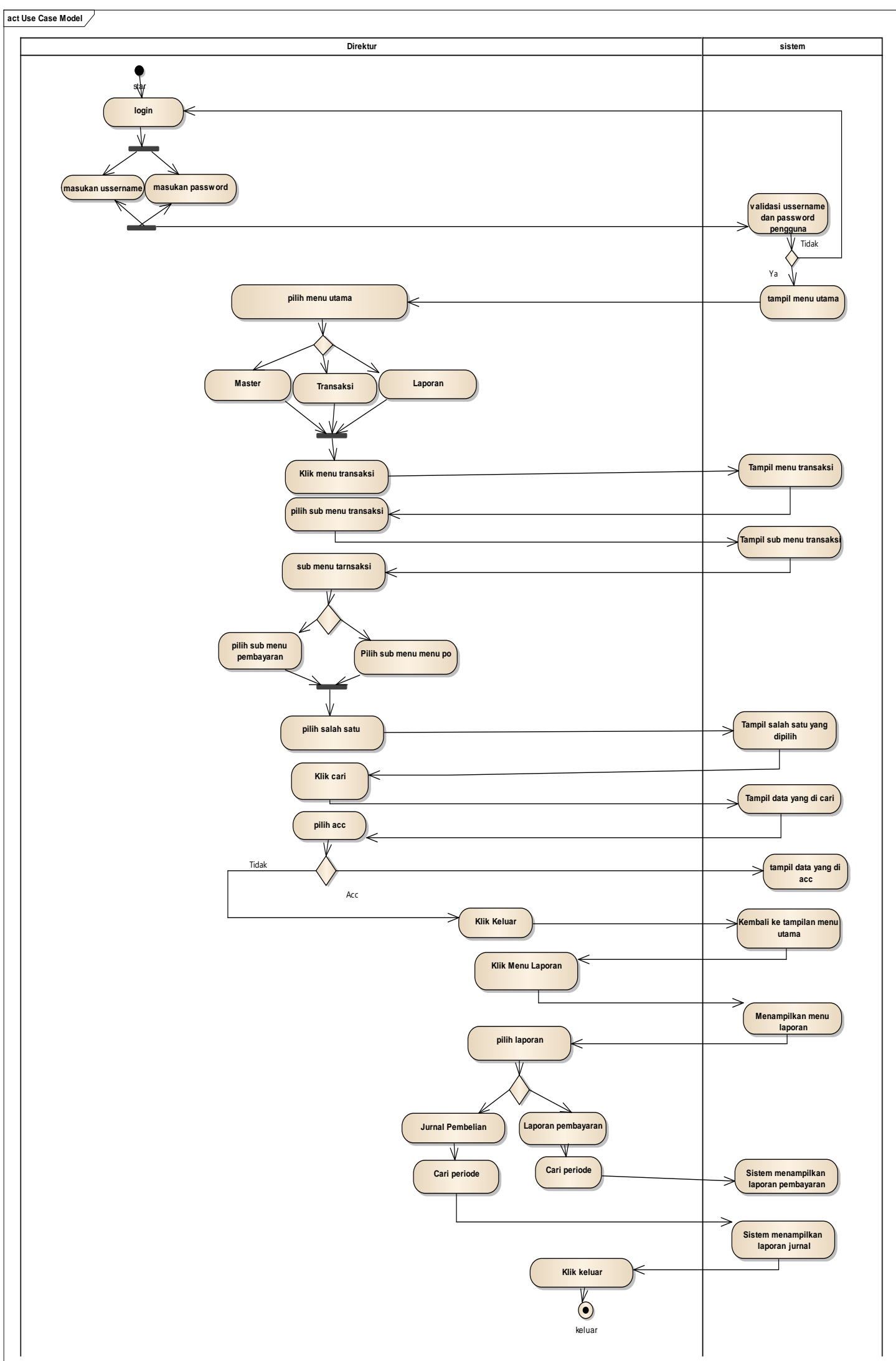

Sumber: Penelitian (2019)

Gambar 6. Use case Diagram Direktur 


\section{ERD (Entity Relationship Diagram)}

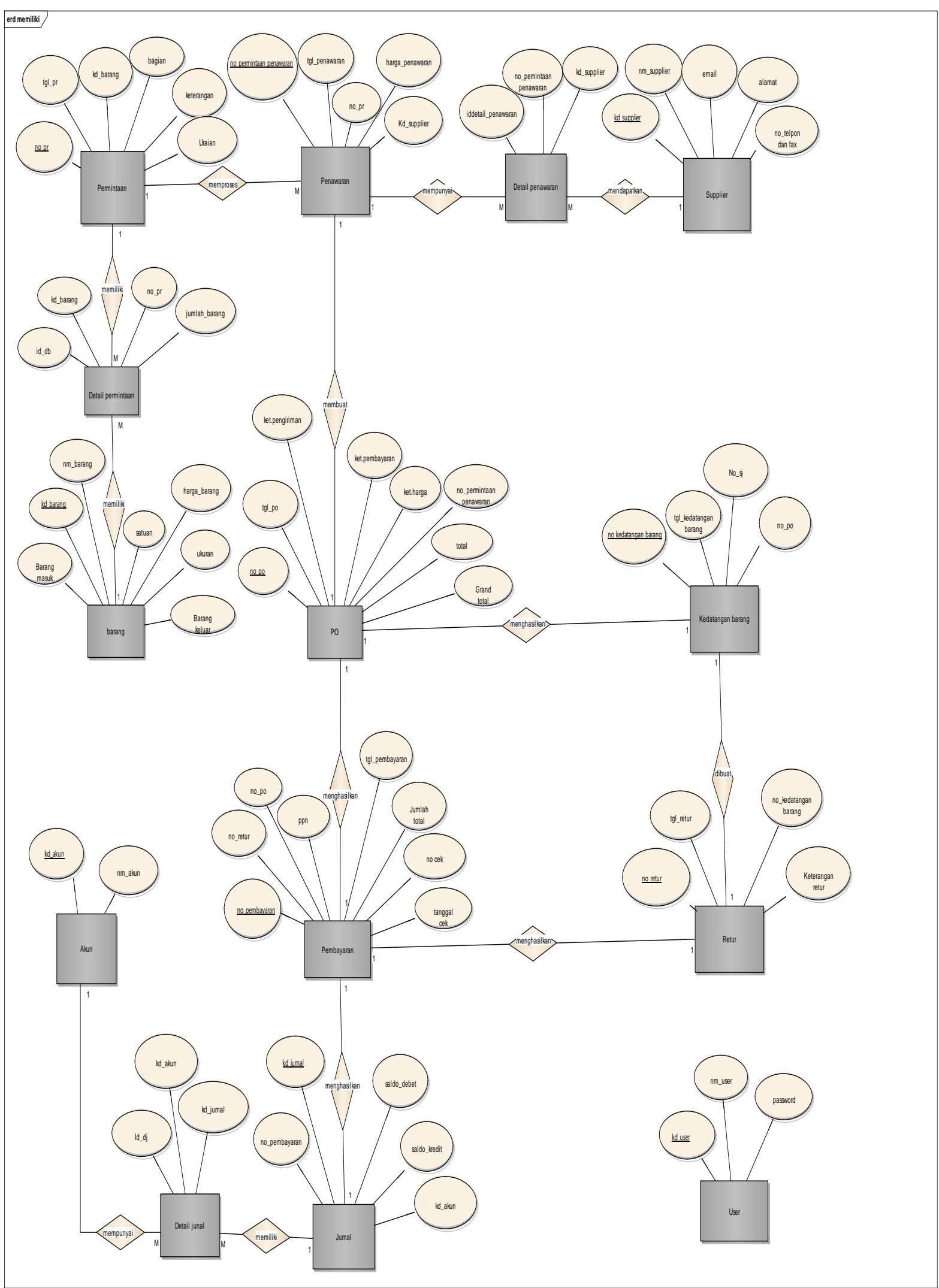

Sumber: Penelitian (2019) 


\section{Deployment Diagram Pembelian Bahan Baku}

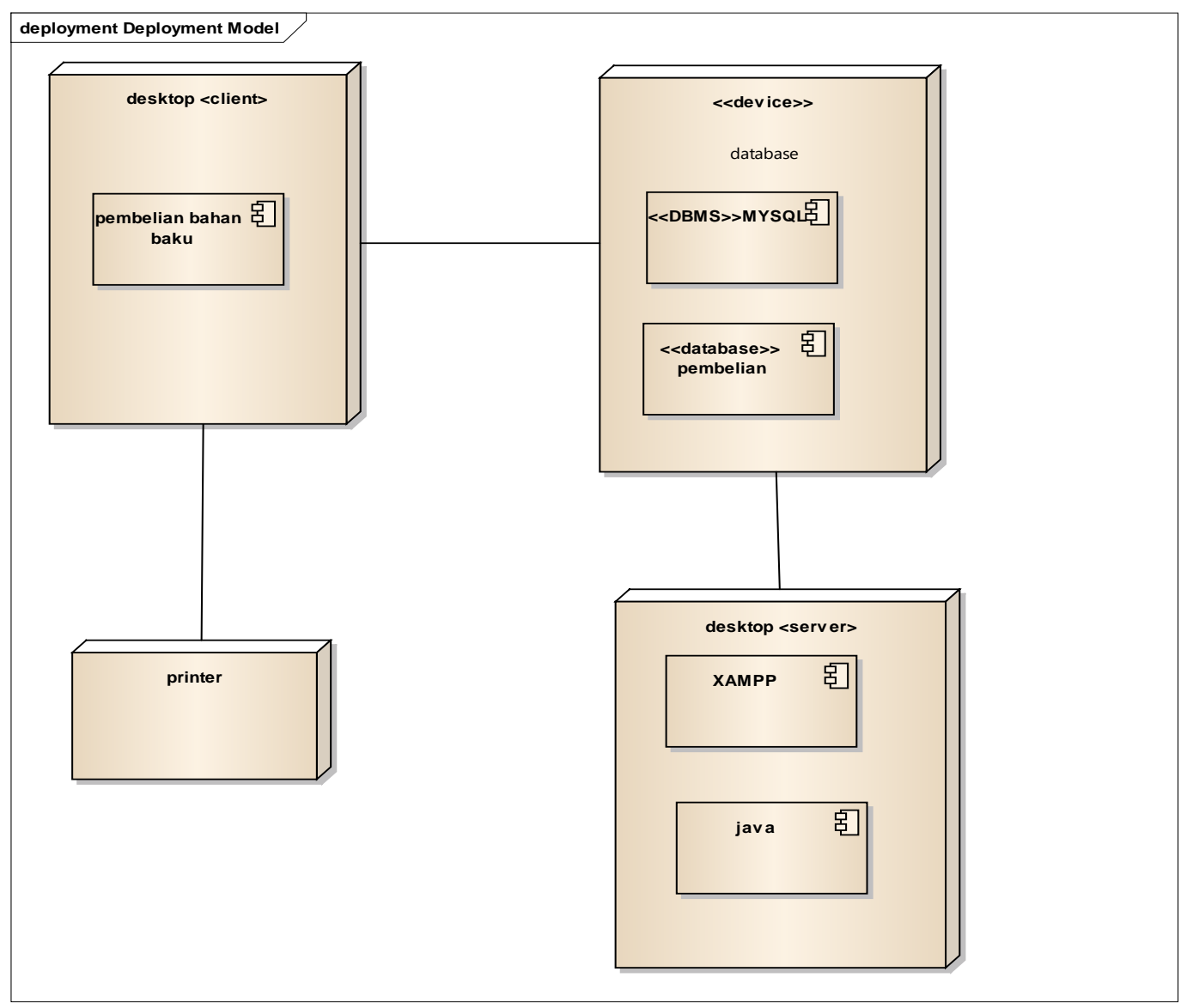

Sumber: Penelitian (2019)

Gambar 8. ERD Pembelian Bahan Baku 